\title{
Functional improvement in hip pathology is related to improvement in anxiety, depression, and pain catastrophizing: an intricate link between physical and mental well-being
}

Paul Gudmundsson ${ }^{1}$, Paul A. Nakonezny ${ }^{2}$, Jason Lin ${ }^{1}$, Rebisi Owhonda ${ }^{1}$, Heather Richard ${ }^{3}$ and Joel Wells ${ }^{1 *}$ (D)

\begin{abstract}
Background: Pain catastrophizing, anxiety, and depression are risk factors for poor functional outcomes and worse post-treatment pain that can be treated alongside physical care given to orthopedic patients. While these factors have been shown to be common in patients with hip pathology, there is limited literature that follows these conditions throughout treatment. The purpose of this study was to track psychological factors in patients with various hip pathology to determine if they improved alongside functional measures following treatment.

Methods: Patients presenting to a specialist hip clinic were prospectively evaluated for outcomes of pain catastrophizing, anxiety, depression, and hip function. Pre- and post-treatment assessments were undertaken: Pain Catastrophizing Scale, the Hospital Anxiety Depression Scale, the Hip Outcome Survey, and Hip Disability and Osteoarthritis Outcome Score (HOOS). Patient characteristics were recorded. A correlation analysis, using the Spearman partial correlation coefficient $\left(r_{s}\right)$, was conducted to evaluate the relationship between change in psychological factors with change in functional outcomes.
\end{abstract}

Results: A total of 201 patients (78 male, 123 female) with a mean age of $53.75 \pm 18.97$ years were included, with diagnoses of hip dysplasia $(n=35)$, femoroacetabular impingement $(n=35)$, lateral trochanteric pain syndrome $(n=$ 9), osteoarthrosis $(n=109)$, and avascular necrosis of the hip $(n=13)$. Statistical analysis revealed a significant negative relationship between change in function level (as measured by HOOS ADL) and change in pain catastrophizing $\left(r_{s}=-0.373, p<0.0001\right)$, depression $\left(r_{s}=-0.363, p<0.0001\right)$, and anxiety $\left(r_{s}=-0.264, p=0.0002\right)$. Pain catastrophizing, depression, and anxiety improved with function. Spearman correlation coefficients also revealed that pain catastrophizing, HADS anxiety, and HADS depression improved with improvement in other patient-reported functional outcomes.

(Continued on next page)

* Correspondence: jobuwells@gmail.com

'Department of Orthopaedic Surgery, University of Texas Southwestern

Medical Center, 1801 Inwood Rd, Dallas, TX 75390, USA

Full list of author information is available at the end of the article

(c) The Author(s). 2021 Open Access This article is licensed under a Creative Commons Attribution 4.0 International License, which permits use, sharing, adaptation, distribution and reproduction in any medium or format, as long as you give appropriate credit to the original author(s) and the source, provide a link to the Creative Commons licence, and indicate if changes were made. The images or other third party material in this article are included in the article's Creative Commons licence, unless indicated otherwise in a credit line to the material. If material is not included in the article's Creative Commons licence and your intended use is not permitted by statutory regulation or exceeds the permitted use, you will need to obtain permission directly from the copyright holder. To view a copy of this licence, visit http://creativecommons.org/licenses/by/4.0/. The Creative Commons Public Domain Dedication waiver (http://creativecommons.org/publicdomain/zero/1.0/) applies to the data made available in this article, unless otherwise stated in a credit line to the data. 


\begin{abstract}
(Continued from previous page)
Conclusions: Patients with hip pathology often exhibit pain catastrophizing, anxiety, and depression, but improvements in hip functionality are associated with decreased severity of these psychological comorbidities. Exploring this connection demonstrates the correlation between musculoskeletal impairment and psychosocial outcomes and mental health. Perioperative multidisciplinary assessment may be a beneficial part of comprehensive orthopaedic hip care.
\end{abstract}

Keywords: Pain catastrophizing, Hip function, Outcomes, Mental health

\section{Background}

Hip pain contributes to reductions in physical function and ability, but pain is a subjective experience that represents a confluence of biological, social, and psychological factors. The development of hip pain is multifactorial, affected by pathologic factors like hip morphology, arthrosis, and musculotendinous injury, as well as externally-related contributors like BMI, comorbid conditions, and mental health [1-5]. Pain catastrophizing, anxiety, and depression have been shown to play a role in patients' pain and function, secondary to orthopedic conditions like osteoarthritis [2, 3, 6, 7].

Pain catastrophizing is defined as an exaggerated negative mental set that arises in response to present or anticipated pain, broken down into subcategories of rumination, magnification, and helplessness [8]. It is associated with patients who consistently report higher levels of perceived pain, leading to longer hospital stays and increased risk of opioid abuse following orthopedic surgery [7, 9]. Anxiety is intensified feelings of fear, worry, and nervousness [10]. Depression is a persistent and abnormal sense of sadness, hopelessness, and loss of self-worth [10]. Each plays a role in a patient's experience of his/her hip condition and should be a part of one's treatment. Attention to these psychological components may represent a clinically important target for the improvement of orthopedic patient health and outcomes [2].

Patients with hip pathology often exhibit levels of pain catastrophizing, anxiety, and depression at the time of presentation [11]. These psychological symptoms represent modifiable risk factors that can be treated alongside the orthopedic diagnosis. There is currently a paucity of research on how an improvement in hip function would affect psychological factors. Thus, the aim of this study was to explore the interplay between patient-reported hip function and the severity of pain catastrophizing, depression, and anxiety following orthopedic treatment.

\section{Methods}

\section{Participants}

We prospectively evaluated patients presenting at a single academic hip clinic, with the main complaint of hip pain, between August 2017 and November 2019. These patients underwent assessment using validated scales following Institutional Review Board approval. They included the Pain Catastrophizing Scale (PCS), the Hospital Anxiety Depression Scale (HADS), a visual analogue pain scale (VAS), the Hip Outcome Survey (HOS), and the Hip Disability and Osteoarthritis Outcome Score (HOOS) [8, 12-18]. These assessments and scales have been previously published and can be found at the above-listed citations. We followed these psychological measures longitudinally throughout physical and functional treatment of patients with symptomatic hip dysplasia (DDH), femoroacetabular impingement syndrome (FAI), lateral trochanteric pain syndrome (LTP), hip osteoarthritis (OA), and avascular necrosis of the hip (AVN). Additionally, the patients were informed that deidentified information from the surveys may be used in future research studies, and thus all of the patients included in this study provided informed consent.

All patients in the study presented with hip pain and diagnostic evaluation including: clinical and radiological examination by an orthopedic surgeon specializing in hip preservation and reconstruction. DDH was diagnosed based on physical and radiological examination with a lateral center-edge Wilberg angle $<20^{\circ}$ [19-23]. FAI was diagnosed based on physical and radiological examination where there was evidence of acetabular over-coverage and/or decreased head and neck offset [19, 21, 24, 25]. The use of such radiographic cutoffs to classify the abnormal hip morphology of DDH and FAI have been shown to be 95\% (95\% CI: 93.7-96.1) and 94.0\% (95\% CI: 92.595.2) accurate, respectively [26]. LTP was diagnosed by physical examination with reproducible pain on palpation, lateral pain on the FABER (flexion abduction external rotation) test, and a normal plain radiograph, a method with mean sensitivity and specificity of 81 and $82 \%$ [27-29]. OA was characterized by a history and physical findings of pain and stiffness of the hip with radiological evidence of OA $[19,30]$. Using this combination of findings to diagnose OA of the hip demonstrates sensitivity and specificity of 36.7 and $90.5 \%$ [19, 30, 31]. AVN was diagnosed by MRI and staged according to the method of Ficat, an approach with specificity $98 \%$ and a sensitivity of $91 \%$ in the differentiation of AVN from normal hips or those with non-AVN disease [32-35]. 
Patients received either operative or non-operative treatment with non-operative being physical therapy or medication/injection. The surgeries included in the operative treatment group consisted of a range of procedures tailored to the specific diagnosis and symptom severity of each patient. These operations included total hip arthroplasty, periacetabular and femoral osteotomy, and minimally invasive hip arthroscopy. Those patients treated with physical therapy were given specific physical therapy scripts including strengthening and range of motion exercises. Medications included anti-inflammatories like steroid injections and NSAIDs. Length of treatment was recorded.

The responses from 201 patients with the diagnosis of DDH, FAI, LTP, OA, or AVN were used in this study, and sample selection was primarily determined by availability of complete pre/post assessments. All patients who presented with hip pain and were ruled to have one of these five diagnoses were eligible for inclusion $(n=$ 1269). These five diagnoses were chosen due to the prevalence of these conditions in the clinic's patient population as well as clinical expertise of the senior author/diagnosing physician. However, because this aim of this study was to track functional and psychological outcomes longitudinally, only data from patients who had completed the above-mentioned assessments prior to and once after treatment were used in this study $(n=$ 410). Furthermore, because all of the patient-reported data required scoring the assessments that were completed by the patients themselves, all patients with surveys deemed to be incomplete were excluded, leading to our final cohort size of 201 patients with complete pre/ post data. This selection process is depicted in Fig. 1.

\section{Procedures and measures}

Patient-level variables obtained from the patient electronic medical record (EMR) included: sex, age, body mass index $\left(\mathrm{BMI}, \mathrm{kg} / \mathrm{m}^{2}\right)$, diagnosis, and treatment protocol (Table 1). The American Society of Anesthesiologists (ASA) classification of physical status was calculated using comorbidities listed in the EMR [36]. A selfreport questionnaire was administered to identify comorbidities (Table 2). Patient-perceived level of pain was also quantified using a visual analogue scale (VAS; $0=$ no pain; 10 = pain as bad as it can be). The Tönnis classification was used to grade the severity of OA (Table 3) [19]. While these categories were not explicitly part of our statistical analysis of functional and psychological outcomes, they are included as descriptive statistics to better characterize our cohort.

\section{Outcome measures}

The primary outcomes were patient-reported pain catastrophizing, anxiety, depression, and hip function pre/ post-treatment. Assessments were gathered using validated questionnaires completed by patients during clinic office visits both before and after treatment, with the follow-up timepoint occurring about six months on average after the completion of treatment. The PCS consists of 13 items, with scores for each question ranging from zero to four. The total score was calculated as the sum of the values of the 13 items, ranging from zero to 52. Higher scores correspond to higher levels of pain catastrophizing. A total score $>30$ is considered clinically significant. HADS is a reliable patient-reported measure assessing symptoms of anxiety and depression [12, 13]. Each item score ranges from zero to three, with zero

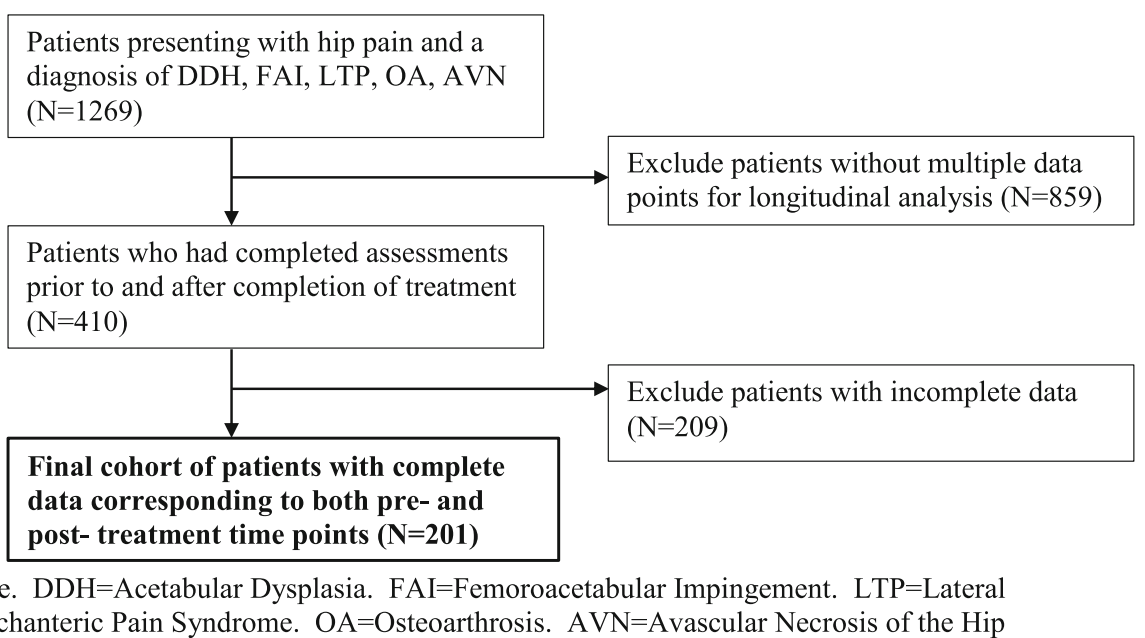

Fig. 1 Consort Diagram of Inclusion and Exclusion Criteria. Note. DDH = Acetabular Dysplasia. FAl=Femoroacetabular Impingement. LTP = Lateral Trochanteric Pain Syndrome. OA = Osteoarthrosis. AVN = Avascular Necrosis of the Hip 
Table 1 Demographic and clinical characteristics of the overall sample

\begin{tabular}{|c|c|}
\hline Characteristic & $\begin{array}{l}\text { Overall Sample } \\
(N=201)\end{array}$ \\
\hline \multicolumn{2}{|l|}{ Patient Demographics } \\
\hline Age, years, M (SD) & $53.75(18.97)$ \\
\hline Female Gender, \% (n) & $61.19(123)$ \\
\hline \multicolumn{2}{|l|}{ Patient Factors } \\
\hline $\mathrm{BMl}, \mathrm{kg} / \mathrm{m}^{2}, \mathrm{M}(\mathrm{SD})$ & $27.24(5.48)$ \\
\hline Time pre- to post-treatment, days, M (SD) & $187.36(125.19)$ \\
\hline \multicolumn{2}{|l|}{ Tonnis Grade, \% (n) } \\
\hline 0 & $22.4(45)$ \\
\hline 1 & $17.9(36)$ \\
\hline 2 & $10.4(21)$ \\
\hline 3 & $49.3(99)$ \\
\hline \multicolumn{2}{|l|}{ ASA Classification, \% (n) } \\
\hline 1 & $36.8(74)$ \\
\hline 2 & $46.8(94)$ \\
\hline 3 & $15.4(31)$ \\
\hline 4 & $1.0(2)$ \\
\hline History of Surgery on Current Hip, \% (n) & $35.8(72)$ \\
\hline \multicolumn{2}{|l|}{ Diagnosis Groups } \\
\hline Femoroacetabular Impingement, \% (n) & $17.4(35)$ \\
\hline Acetabular Dysplasia, \% (n) & $17.4(35)$ \\
\hline Osteoarthrosis, \% (n) & $54.2(109)$ \\
\hline Lateral Trochanteric Pain Syndrome, \% (n) & $4.5(9)$ \\
\hline Avascular Necrosis of the Hip \% (n) & $6.4(13)$ \\
\hline \multicolumn{2}{|l|}{ Treatment Groups } \\
\hline Surgical \% (n) & $83.6(168)$ \\
\hline \multicolumn{2}{|l|}{ Non-surgical \% (n) } \\
\hline Physical Therapy & $11.9(24)$ \\
\hline Medication/Injection & $4.5(9)$ \\
\hline
\end{tabular}

Note. $M$ Sample Mean, SD Standard Deviation. All characteristics were selfreported by the patient

ASA American Society of Anesthesiologists

meaning no symptoms and three denoting that symptoms are felt frequently. Subscales are calculated by adding each item for a possible range of zero to 21. Each subscale score is divided into levels: normal (0 to 7), borderline abnormal (8 to 10$)$, and abnormal (11 to 21$)$.

Measures of patient symptoms and hip function were also included. Patient-perceived level of function was quantified using the HOS and the HOOS scores [16, 17]. The HOS includes activities of daily living (HOS-ADL) and sports (HOS-Sports) subscales. Respectively, each subscale has 17 and nine items that are scored from 0 to 4 ( 0 being unable to perform; 4 being no difficulty). Subscale total scores are summed and normalized so that the final scores are a percent of maximal function. The
Table 2 Patient Comorbidities

\begin{tabular}{ll}
\hline Patient Comorbidities & Patients, $\mathbf{n}(\%)$ \\
\hline Low Back Pain & $111(55.2)$ \\
High Blood Pressure & $67(33.3)$ \\
Cancer & $21(10.4)$ \\
Anemia & $12(6.0)$ \\
Lung Disease & $9(4.5)$ \\
Heart Disease & $12(6.0)$ \\
Liver Disease & $6(3.0)$ \\
Kidney Disease & $7(3.5)$ \\
Diabetes & $12(6.0)$ \\
Ulcer/Stomach Disease & $12(6.0)$ \\
\hline $\begin{array}{l}\text { Note. Numbers represent the number of patients with each comorbidity and } \\
\text { the percent of our cohort that carried each comorbidity. The totals sum to a }\end{array}$ \\
$\begin{array}{l}\text { number larger than our cohort of } 201 \text { patients, as some patients carried more } \\
\text { than one comorbidity }\end{array}$
\end{tabular}

HOOS consists of 40 questions and five subscales related to stiffness (HOOS Stiffness), other symptoms (HOOS Symptoms), ADLs (HOOS ADL), function in sports and recreation (HOOS Sports), and hip-related quality of life (HOOS QOL). Each item is scored 0 to 4 ( 0 indicating extreme trouble and 4 meaning no trouble), and the sum is normalized so that a score of 0 indicated severe impairment and a score of 100 represents no problems.

\section{Statistical analysis}

Demographic and clinical characteristics for the sample of 201 patients with a range of hip pathology were described using the sample mean and standard deviation for continuous variables and the frequency and percentage for categorical variables. The mean level of pain catastrophizing, anxiety, depression, and functional outcome measures at pre and post-treatment was compared using the dependent samples t-test. Next, a correlation analysis, using the Spearman partial correlation coefficient $\left(r_{\mathrm{s}}\right)$, was conducted to evaluate the relationship between change in self-reported pain catastrophizing (PCS total score), HADS depression, and HADS anxiety with change in patient-reported functional outcome measures, while controlling for age, BMI, and time in days from pre- to post-treatment assessment.

Statistical analyses were carried out using SAS software, version 9.4 (SAS Institute, Inc., Cary, NC). The level of significance was set at $\alpha=0.05$ (two-tailed). We implemented the False Discovery Rate (FDR) procedure to control false positives over the multiple tests [37].

\section{Results}

Participant characteristics

The sample of 201 patients were $61.19 \%$ female, mean age of $53.75 \pm 18.97$ years (range $=14$ to 89 years). Mean 
Table 3 Tönnis classification of osteoarthritis

\begin{tabular}{llll}
\hline Grade & Description & Patients, n (\%) \\
\hline 0 & No signs of osteoarthritis & $45(22.4)$ & $36(17.9)$ \\
1 & Mild: increased sclerosis, slight narrowing of the joint space, no or slight loss of head sphericity & $21(10.4)$ & $99(49.3)$ \\
2 & Moderate: small cysts, moderate narrowing of the joint space, moderate loss of head sphericity & Severe: large cysts, severe narrowing or obliteration of the joint space, severe deformity of the head & \\
3 & &
\end{tabular}

BMI was $27.24 \pm 5.48 \mathrm{~kg} / \mathrm{m}^{2}$. The surgical group included 168 patients, while the non-operative group included 33 patients (physical therapy $=24$, medication/ injection $=9$ ). The mean time in days from pre- to posttreatment assessment was $187.36 \pm 125.19$ days (range = 28 to 725 days). The sample included $35 \mathrm{DDH}$ patients, 35 with FAI, 9 with LTP, 109 with OA, and 13 with AVN. Demographic and clinical characteristics are shown in Table 1.

\section{Change in PCS, HADS, and functional outcomes}

The dependent samples t-test revealed statistically significant improvement in mean levels of pain catastrophizing $(p<0.0001)$, anxiety $(p<0.0001)$, depression $(p<0.0001)$, and functional outcomes $(p<0.0001)$ from pre- to post-treatment for patients with adverse hip conditions (Table 4).

\section{Correlation between change in PCS and HADS with change in functional outcomes}

The Spearman partial correlation coefficients revealed a significant negative relationship between change in level of function (measured by the HOOS ADL) and change in pain catastrophizing $\left(r_{s}=-0.373, p<0.0001\right)$, change in HADS depression $\left(r_{s}=-0.363, \mathrm{p}<0.0001\right)$, and change in HADS anxiety $\left(r_{s}=-0.264, p=0.0002\right)$, while controlling for age, BMI, and time in days from pre- to post-treatment assessment. Pain catastrophizing, depression, and anxiety improved as level of function (ADL) improved. Spearman correlation coefficients revealed that pain catastrophizing, HADS anxiety, and HADS depression improved with improvement in the other patient-reported functional outcomes (Table 5). Of the functional outcomes, the Spearman correlation coefficients revealed that improvement in HOOS ADL can be interpreted as having a greater magnitude of relative importance in the expected relationship with improvement in PCS Total and HADS Depression/Anxiety.

\section{Discussion}

The role of psychological factors, like that of pain catastrophizing, anxiety, and depression, in the presentation of orthopedic symptoms and patient-reported pain are becoming more recognized [1-3, 6, 11, 38]. Hampton et al. demonstrated that patients with hip pathology also present with levels of pain catastrophizing, anxiety, and depression. Hip pain and dysfunction may play a significant role in a patient's psychological well-being [11]. We further explored this association between function and psychology; specifically, a link between improved activity

Table 4 Change in mean levels of pain catastrophizing, anxiety, depression, and function from pre- to post-treatment for patients with adverse hip conditions

\begin{tabular}{|c|c|c|c|c|c|}
\hline & $N$ & $\begin{array}{l}\text { Pretreatment } \\
M(S D)\end{array}$ & $\begin{array}{l}\text { Posttreatment } \\
M(S D)\end{array}$ & $\begin{array}{l}\Delta_{M} \\
M(S D)\end{array}$ & $p$-value \\
\hline \multicolumn{6}{|l|}{ Outcome } \\
\hline PCS Total & 201 & 15.94 (12.73) & $8.26(10.57)$ & $-7.67(11.70)$ & $<0.0001$ \\
\hline VAS Pain & 201 & $5.21(2.35)$ & $2.51(2.50)$ & $-2.70(3.11)$ & $<0.0001$ \\
\hline HADS Depression & 201 & $5.42(3.72)$ & $3.83(3.61)$ & $-1.59(3.96)$ & $<0.0001$ \\
\hline HADS Anxiety & 201 & $5.43(3.02)$ & $3.90(4.07)$ & $-1.53(4.11)$ & $<0.0001$ \\
\hline HOS Function & 201 & $1.91(0.68)$ & $2.70(0.81)$ & $0.79(1.03)$ & $<0.0001$ \\
\hline HOOS ADL & 201 & $46.45(17.40)$ & $65.23(15.76)$ & 18.77 (21.39) & $<0.0001$ \\
\hline HOOS Symptoms & 201 & 41.04 (19.88) & 64.04 (17.79) & $23.00(26.12)$ & $<0.0001$ \\
\hline HOOS Stiffness & 201 & 38.95 (20.45) & 58.65 (19.43) & $19.70(26.92)$ & $<0.0001$ \\
\hline HOOS Sport & 201 & 30.43 (22.94) & $50.26(25.20)$ & $19.83(32.51)$ & $<0.0001$ \\
\hline HOOS QoL & 201 & $20.98(17.47)$ & $49.18(24.04)$ & $28.20(28.52)$ & $<0.0001$ \\
\hline
\end{tabular}

Note. $M=$ Sample Mean; $S D=$ Standard Deviation; $\Delta_{M}=$ Mean change in outcome. Change was operationally defined as post minus pre level. $p$-value (two-tailed) = Dependent samples t-test was used to test for differences in sample means from pre- to post-treatment. FDR values were all 0.0001 PCS Pain Catastrophizing Scale, VAS Visual Analogue Pain Scale, HADS Hospital Anxiety and Depression Scale, HOS Hip Outcome Survey, HOOS Hip Disability and Osteoarthritis Outcome Score 
Table 5 Spearman correlation coefficients $\left(r_{s}\right)$ between the change in PCS and HADS with the change in Functional Outcomes

\begin{tabular}{lllll}
\hline Change in Level of Function & N & $\mathbf{r}_{\mathbf{s}}$ & p-value & FDR \\
\hline HOS Function & \multicolumn{4}{l}{ Change in PCS Total } \\
HOOS ADL & 201 & -0.298 & 0.0001 & 0.0003 \\
HOOS Symptoms & 201 & -0.373 & 0.0001 & 0.0003 \\
HOOS Stiffness & 201 & -0.216 & 0.0022 & 0.0026 \\
HOOS Sport & 201 & -0.200 & 0.0046 & 0.0046 \\
HOOS QoL & 201 & -0.264 & 0.0002 & 0.0004 \\
& 201 & -0.254 & 0.0003 & 0.0005 \\
HOS Function & Change in HADS Depression \\
HOOS ADL & 201 & -0.317 & 0.0001 & 0.0001 \\
HOOS Symptoms & 201 & -0.363 & 0.0001 & 0.0001 \\
HOOS Stiffness & 201 & -0.298 & 0.0001 & 0.0001 \\
HOOS Sport & 201 & -0.221 & 0.0017 & 0.0017 \\
HOOS QoL & 201 & -0.272 & 0.0001 & 0.0001 \\
& 201 & -0.271 & 0.0001 & 0.0001 \\
HOS Function & Change in HADS Anxiety & \\
HOOS ADL & 201 & -0.129 & 0.0690 & 0.0828 \\
HOOS Symptoms & 201 & -0.264 & 0.0002 & 0.0012 \\
HOOS Stiffness & 201 & -0.177 & 0.0123 & 0.0369 \\
HOOS Sport & 201 & -0.155 & 0.0290 & 0.0580 \\
HOOS QoL & 201 & -0.133 & 0.0617 & 0.0828 \\
\hline & 201 & -0.105 & 0.1373 & 0.1373 \\
\hline
\end{tabular}

Note. Change was operationally defined as post minus pre level. $p$-value $=$ Two-tailed test on Spearman's Rho. FDR False Discovery Rate, HOS Hip Outcome Survey, HOOS Hip Disability and Osteoarthritis Outcome Score, PCS Pain Catastrophizing Scale, HADS Hospital Anxiety and Depression Scale

of daily living function and improved psychological factors.

Our primary aim was to assess the relationship between functional improvement and levels of pain catastrophizing, anxiety, and depression. Hip function was measured in terms of the patients' subjective assessment of their hips, rather than with performance-based functional metrics. In patients with differing hip pathologies, we found that patients endorsed a greater level of function after treatment, as measured by scores of HOS function and each of the HOOS subcategories. The most improved absolute measurements from pre-to-post treatment include the HOOS Sports, HOOS Symptoms and HOOS QoL subcategories; thus, patients endorsed the most functional improvement in lower stress, dayto-day activities. Additionally, patients endorsed a lower level of average pain following treatment, as measured by the VAS.

Assessment of the psychological parameters of this study began by establishing the levels of pain catastrophizing, anxiety, and depression present in our patients prior to their onset of treatment. Untreated patients presenting with hip pain were affected by clinically significant levels of each of these factors prior to treatment, regardless of their diagnosis. This link between hip pathology and mental health status has been previously documented in OA, FAI, and DDH [2, 3, 7-9, 11, 39]. Additionally, it has been previously shown that this relationship is quantifiable, as higher reported subjective functioning in hip patients is associated with lower levels of pain catastrophizing, anxiety, and depression at time of presentation [11, 38]. In our cohort, pain catastrophizing scores were particularly elevated in patients with lower function scores, as difficulties with activities of daily living, and the resulting loss of self-sufficiency, lend themselves to pain catastrophizing $[8,40]$.

After assessing the psychological profile of our cohort prior to treatment, we next determined how each measured psychological category changed following treatment. Psychologic improvement may not always occur following treatment, as previous studies have shown that significant levels of various psychiatric conditions can be present after treatment of orthopedic conditions [41, 42]. In a study of comorbidity progression following arthroscopic hip surgery, it is shown that psychological issues can worsen following treatment, perhaps due to dissatisfaction with the level of postoperative functional improvement [43]. There is no association that shows that treatment itself directly improves psychological metrics if the patient does not experience an improvement in level of function. Our results support that improvement in the mental health measures is associated with the effectiveness of treatment on improving hip function and overall quality of life.

Although improvement of each of the functional outcomes showed correlation with improvement in pain catastrophizing, HADS anxiety, and HADS depression, our results demonstrate that improvement in HOOS ADL has the greatest magnitude of importance in the relationship with improvement in pain catastrophizing and HADS Depression/Anxiety. Loss of ADL independence has been shown to cause large declines in mental health, as functional impairment and pain have a strong impact on daily life, causing patients to avoid situations and activities that require the use of their problematic hip [44, 45]. Conversely, it has been shown that relief from the factors that limit independence and social engagement can reduce feeling of helplessness and isolation, directly impacting feelings of depression and anxiety [46, 47]. Our results support this supposition: improved hip function and the decreased burden felt in ADL has a strong relationship with the improvement of mental health. Because activities of daily living represent such a large part of a patient's quality of life it is likely that patients are more aware of their impairment if such activities are 
affected. Thus, functional improvement that reduces difficulty with ADL may have a particularly strong effect on overall wellness.

Of the psychological metrics that tended to improve alongside increased function, the pain catastrophizing total score demonstrated the most relative improvement. Pain catastrophizing is an important pain-related variable that has been adversely linked to disability and quality of life in patients with both hip and knee OA $[48,49]$. As pain catastrophizing is an exaggerated negative mental state during painful experience, it is a logical conclusion that decreased pain and increased function reduce catastrophizing [8]. Our results support this link, revealing a trend of decreased PCS scores as functional assessment improves. As patients feel less hindered by their hip condition, their expectation and anticipation of associated pain and disability decreases accordingly.

There are a few limitations of this study. The cohort of patients included in this study presented to one specialist, and may not reflect all hip patients in a general population. Patients suffering from OA represented a majority of the diagnoses, and the small sample size of diagnoses like LTP and AVN prevented our ability to run a stratified analysis on each subgroup. However, because we are investigating the interplay between overall hip function and its impact on psychosocial health rather than any specific disease-modifying process, we deemed it appropriate to analyze our overall cohort. Additionally, our assessments lack standardization in both length of time from the pre- to post-treatment measurement as well as treatment protocol. Although about $85 \%$ of patients received surgery (compared to about $15 \%$ who received non-operative treatment) and we statistically controlled for length of time from pre-topost treatment, the wide range in time elapsed between pre/post assessments and the varying treatment modalities may confound our results. However, we also note that the varying treatment modalities along with the time elapsed between assessments represent a real-life clinic setting-not an artificially-controlled settingwhich bolsters the external validity of the current study.

Finally, concern regarding the validity and reliability of using self-report measures to evaluate musculoskeletal complaints has been documented in previous literature $[50,51]$. We attempted to addressed this issue by using validated assessments, but our reliance on using patientreported outcomes to determine hip functionality and psychological comorbidity could affect the internal validity of the study.

\section{Conclusions}

In conclusion, we found that improvements in pain catastrophizing, depression, and anxiety are associated with better patient-reported hip function. Patients who originally presented with clinically significant levels of pain catastrophizing, anxiety, and depression demonstrated a decreased severity of these mental health conditions following treatment that improved their hip function. Additionally, our results show the effect that functional improvements may have on psychological factors; conversely, it may also be true that improvements in patients' psychology and mental outlook may contribute to achieving optimal functional improvements for various musculoskeletal and orthopedic conditions. Because of the association between psychological factors and hip function, we believe that mental health factors may represent an important treatment target to consider as part of a multidisciplinary approach toward treatment of orthopedic hip conditions.

\section{Supplementary Information}

The online version contains supplementary material available at https://doi. org/10.1186/s12891-021-04001-5.

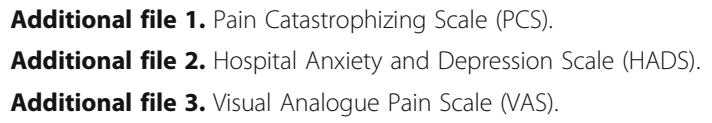

\section{Abbreviations}

ADL: Activities of Daily Living; AVN: Avascular Necrosis of the Hip; BMI: Body Mass Index; DDH: Developmental Dysplasia of the Hip; EMR: Electronic Medical Record; FABER: Flexion Abduction External Rotation Test; FAl: Femoroacetabular Impingement Syndrome; HADS: Hospital and Anxiety Depression Score; HOOS: Hip Disability and Osteoarthritis Outcome Score; HOS: Hip Outcome Survey; LTP: Lateral Trochanteric Pain Syndrome; MRI: Magnetic Resonance Imaging; OA: Osteoarthritis of the Hip; PCS: Pain Catastrophizing Scale; QOL: Quality of Life; VAS: Visual Analogue Pain Scale

\section{Acknowledgements \\ $\mathrm{n} / \mathrm{a}$}

\section{Authors' contributions}

JW conceived the idea for this study. He was also a major contributor in writing the manuscript and leading the analysis and interpretation of the impact of functional hip improvement on mental health. PG was the primary author of the manuscript and assisted with study design, data collection, and analysis. PN performed the statistical analysis for the study and wrote the corresponding part of the Methods section. $J \mathrm{~L}$ and RO assisted with data collection. HR edited the of the manuscript and provided specific insight into the psychology-related aspects of the paper. All authors read and approved the final manuscript.

\section{Authors' information}

Dr. Joel Wells is an assistant professor in the Department of Orthopaedic Surgery at UT Southwestern Medical School. He completed residency at the Harvard combined program. He then received advanced training in joint preservation, resurfacing, and reconstructive surgery through a fellowship at Washington University in St. Louis. He now tends to the Dallas population with an emphasis on hip symptomatology and preservation in patients of all ages. Paul Gudmundsson and Jason Lin are medical students at UT Southwestern Medical School. Rebisi Owhonda is a medical student at UTRGV School of Medicine. Each of these three students are interested in pursuing a residency training and career in Orthopedic Surgery. Paul Nakonezny is an Associate Professor of Biostatistics in the Department of Clinical Sciences, Division of Biostatistics. He also holds a secondary faculty appointment in the Department of Psychiatry. Dr. Nakonezny has considerable experience in statistical methods and application of such methods to clinical research, including clinical trials, observational, and 
epidemiologic studies. Heather Richard, Psy.D., is a pediatric psychologist who has provided psychological consultation and care to children at Scottish Rite for Children for over 12 years. She completed her internship in Health Psychology at the VA North Texas Medical Center and her fellowship at Scottish Rite. She received her Master's and Doctoral degrees in Clinical Psychology at Nova Southeastern University.

\section{Funding}

JW was awarded the Hoglund Foundation Hip Research Grant in 2019. The funding body had no role in the design of the study, the collection, analysis, and interpretation of data, or the writing of the manuscript.

\section{Availability of data and materials}

The datasets generated and/or analyzed during the current study are not publicly available due concern for patient privacy but are available from the corresponding author on reasonable request.

\section{Ethics approval and consent to participate}

IRB approved research study STU 122016-058 at the University of Texas Southwestern, all patients gave written consent to participate.

\section{Consent for publication}

Not Applicable.

\section{Competing interests}

No financial/non-financial competing interests to report.

\section{Author details}

${ }^{1}$ Department of Orthopaedic Surgery, University of Texas Southwestern Medical Center, 1801 Inwood Rd, Dallas, TX 75390, USA. Department of Population and Data Sciences, Division of Biostatistics, University of Texas Southwestern Medical Center, Dallas, USA. ${ }^{3}$ Department of Psychology, TX Scottish Rite Hospital, Dallas, USA.

\section{Received: 15 September 2020 Accepted: 20 January 2021}

\section{Published online: 03 February 2021}

\section{References}

1. Wood TJ, Thornley P, Petruccelli D, Kabali C, Winemaker M, de Beer J. Preoperative predictors of pain Catastrophizing, Anxiety, and depression in patients undergoing Total joint Arthroplasty. J Arthroplast. 2016;31(12): 2750-6.

2. Bierke S, Petersen W. Influence of anxiety and pain catastrophizing on the course of pain within the first year after uncomplicated total knee replacement: a prospective study. Arch Orthop Trauma Surg. 2017;137(12): 1735-42.

3. Gandhi R, Tsvetkov D, Dhottar H, Davey JR, Mahomed NN. Quantifying the pain experience in hip and knee osteoarthritis. Pain Res Manag. 2010;15(4): 224-8.

4. Wasko MK, Yanik EL, Pascual-Garrido C, Clohisy JC. Psychometric properties of patient-reported outcome measures for Periacetabular osteotomy. J Bone Joint Surg Am. 2019;101(6):e21.

5. Tilbury C, Haanstra TM, Verdegaal SHM, Nelissen R, de Vet HCW, Vliet Vlieland TPM, et al. Patients' pre-operative general and specific outcome expectations predict postoperative pain and function after total knee and total hip arthroplasties. Scand J Pain. 2018;18(3):457-66.

6. Jacobs CA, Burnham JM, Jochimsen KN, Molina D, Hamilton DA, Duncan ST. Preoperative symptoms in Femoroacetabular impingement patients are more related to mental health scores than the severity of Labral tear or magnitude of bony deformity. J Arthroplast. 2017;32(12):3603-6.

7. Wright D, Hoang M, Sofine A, Silva JP, Schwarzkopf R. Pain catastrophizing as a predictor for postoperative pain and opiate consumption in total joint arthroplasty patients. Arch Orthop Trauma Surg. 2017;137(12):1623-9.

8. Sullivan M, BS, Pivik J. The Pain Catastrophizing Scale: Development and Validation. Psychol Assess. 1995:7-524.

9. Dunn LK, Durieux ME, Fernandez LG, Tsang S, Smith-Straesser EE, Jhaveri HF, et al. Influence of catastrophizing, anxiety, and depression on in-hospital opioid consumption, pain, and quality of recovery after adult spine surgery. J Neurosurg Spine. 2018;28(1):119-26.
10. Bjelland I, Dahl AA, Haug TT, Neckelmann D. The validity of the hospital Anxiety and depression Scale. An updated literature review. J Psychosom Res. 2002;52(2):69-77.

11. Hampton SN, Nakonezny PA, Richard HM, Wells JE. Pain catastrophizing, anxiety, and depression in hip pathology. Bone Joint J. 2019;101-B(7):800-7.

12. Snaith RP. The Hospital Anxiety and Depression Scale. Health Qual Life Outcomes 2003;1:29

13. Zigmond AS, RS. THe Hospital Anxiety and Depression Scale. Acta Psychiatr Scand. 1983;67:361-70.

14. Haefeli M, Elfering A. Pain assessment. Eur Spine J. 2006;15(Suppl 1):S17-24.

15. Naal FD, Impellizzeri FM, von Eisenhart-Rothe R, Mannion AF, Leunig M. Reproducibility, validity, and responsiveness of the hip outcome score in patients with end-stage hip osteoarthritis. Arthritis Care Res (Hoboken). 2012;64(11):1770-5.

16. Klassbo M, Larsson E, Mannevik E. Hip disability and osteoarthritis outcome score. An extension of the Western Ontario and McMaster universities osteoarthritis index. Scand J Rheumatol. 2003;32(1):46-51.

17. Nilsdotter AK, Lohmander LS, Klassbo M, Roos EM. Hip disability and osteoarthritis outcome score (HOOS)--validity and responsiveness in total hip replacement. BMC Musculoskelet Disord. 2003;4:10.

18. Ashby E, MG, Haddad FS. Outcome measures for orthopaedic interventions of the hip. J Bone Joint Surg. 2018;90-B:545-9.

19. Tonnis D, Heinecke A. Acetabular and femoral anteversion: relationship with osteoarthritis of the hip. J Bone Joint Surg Am. 1999;81(12):1747-70.

20. Clohisy JC, Keeney JA, Schoenecker PL. Preliminary assessment and treatment guidelines for hip disorders in young adults. Clin Orthop Relat Res. 2005;441:168-79.

21. Clohisy JC, Beaule PE, O'Malley A, Safran MR, Schoenecker P. AOA symposium. Hip disease in the young adult: current concepts of etiology and surgical treatment. J Bone Joint Surg Am. 2008;90(10):2267-81.

22. Wells J, Nepple JJ, Crook K, Ross JR, Bedi A, Schoenecker P, et al. Femoral morphology in the dysplastic hip: three-dimensional characterizations with CT. Clin Orthop Relat Res. 2017;475(4):1045-54.

23. Wells J, Schoenecker P, Duncan S, Goss CW, Thomason K, Clohisy JC. Intermediate-term hip survivorship and patient-reported outcomes of Periacetabular osteotomy: The Washington University experience. J Bone Joint Surg Am. 2018;100(3):218-25.

24. Bedi A, Kelly BT. Femoroacetabular impingement. J Bone Joint Surg Am 2013;95(1):82-92.

25. Audenaert EA, Peeters I, Vigneron L, Baelde N, Pattyn C. Hip morphological characteristics and range of internal rotation in femoroacetabular impingement. Am J Sports Med. 2012;40(6):1329-36.

26. Werner CM, Ramseier LE, Ruckstuhl T, Stromberg J, Copeland CE, Turen CH, et al. Normal values of Wiberg's lateral center-edge angle and Lequesne's acetabular index--a coxometric update. Skelet Radiol. 2012;41(10):1273-8.

27. Williams BS, Cohen SP. Greater trochanteric pain syndrome: a review of anatomy, diagnosis and treatment. Anesth Analg. 2009;108(5):1662-70.

28. Mallow M, Nazarian LN. Greater trochanteric pain syndrome diagnosis and treatment. Phys Med Rehabil Clin N Am. 2014:25(2):279-89.

29. Fearon AM, Scarvell JM, Neeman T, Cook JL, Cormick W, Smith PN. Greater trochanteric pain syndrome: defining the clinical syndrome. Br J Sports Med. 2013;47(10):649-53.

30. Allen KD, Renner JB, Devellis B, Helmick CG, Jordan JM. Osteoarthritis and sleep: the Johnston County osteoarthritis project. J Rheumatol. 2008;35(6): 1102-7.

31. Kim C, Nevitt MC, Niu J, Clancy MM, Lane NE, Link TM, et al. Association of hip pain with radiographic evidence of hip osteoarthritis: diagnostic test study. BMJ. 2015;351:h5983.

32. Liu LH, Zhang QY, Sun W, Li ZR, Gao FQ. Corticosteroid-induced osteonecrosis of the femoral head: detection, diagnosis, and treatment in earlier stages. Chin Med J. 2017;130(21):2601-7.

33. Guerado E, Caso E. The physiopathology of avascular necrosis of the femoral head: an update. Injury. 2016;47(Suppl 6):S16-26.

34. Schmitt-Sody M, Kirchhoff C, Mayer W, Goebel M, Jansson V. Avascular necrosis of the femoral head: inter- and intraobserver variations of Ficat and ARCO classifications. Int Orthop. 2008;32(3):283-7.

35. Glickstein MF, Burk DL Jr, Schiebler ML, Cohen EK, Dalinka MK, Steinberg ME, et al. Avascular necrosis versus other diseases of the hip: sensitivity of MR imaging. Radiology. 1988;169(1):213-5.

36. DJ Doyle EG. American Society of Anesthesiologists Classification (ASA class). StatPearls. 2018. 
37. Benjamini Y, YH. Controlling the False Discovery Rate: A Practical and Powerful Approach to Multiple Testing. J R Stat Soc Series B Stat Methodol. 1995;67:289-300.

38. Vissers MM, Bussmann JB, Verhaar JA, Busschbach JJ, Bierma-Zeinstra SM, Reijman M. Psychological factors affecting the outcome of total hip and knee arthroplasty: a systematic review. Semin Arthritis Rheum. 2012;41(4): 576-88.

39. Prather $\mathrm{H}$, Creighton $\mathrm{A}$, Sorenson $\mathrm{C}$, Simpson $\mathrm{S}$, Reese M, Hunt $\mathrm{D}$, et al. Anxiety and insomnia in young and middle-aged adult hip pain patients with and without Femoroacetabular impingement and developmental hip dysplasia. PM R. 2018;10(5):455-61.

40. Leung L. Pain catastrophizing: an updated review. Indian J Psychol Med. 2012;34(3):204-17.

41. Dumenci L, Perera RA, Keefe FJ, Ang DC, Slover J, Jensen MP, et al. Modelbased pain and function outcome trajectory types for patients undergoing knee arthroplasty: a secondary analysis from a randomized clinical trial. Osteoarthr Cartil. 2019;27(6):878-84.

42. Fitzsimmons M, Carr E, Woodhouse L, Bostick GP. Development and persistence of suspected neuropathic pain after Total knee Arthroplasty in individuals with osteoarthritis. PM R. 2018;10(9):903-9.

43. Rhon DI, Greenlee TA, Marchant BG, Sissel CD, Cook CE. Comorbidities in the first 2 years after arthroscopic hip surgery: substantial increases in mental health disorders, chronic pain, substance abuse and cardiometabolic conditions. Br J Sports Med. 2019;53(9):547-53.

44. Albanese AM, Bartz-Overman C, Parikh Md T, Thielke SM. Associations Between Activities of Daily Living Independence and Mental Health Status Among Medicare Managed Care Patients. J Am Geriatr Soc. 2020;68(6):13016.

45. Li X, Wang J, Dong S, Fu J, Liu J. The influence of disabilities in activities of daily living on successful aging: The role of well-being and residence location. Front Public Health. 2019;7:417.

46. Stamm TA, Pieber K, Crevenna R, Dorner TE. Impairment in the activities of daily living in older adults with and without osteoporosis, osteoarthritis and chronic back pain: a secondary analysis of population-based health survey data. BMC Musculoskelet Disord. 2016;17:139.

47. Lin CH, Yen YC, Chen MC, Chen CC. Relief of depression and pain improves daily functioning and quality of life in patients with major depressive disorder. Prog Neuro-Psychopharmacol Biol Psychiatry. 2013;47:93-8.

48. Birch S, Stilling M, Mechlenburg I, Hansen TB. The association between pain catastrophizing, physical function and pain in a cohort of patients undergoing knee arthroplasty. BMC Musculoskelet Disord. 2019;20(1):421.

49. Hayashi K, Morishima T, Ikemoto T, Miyagawa H, Okamoto T, Ushida T, et al. Pain Catastrophizing is independently associated with quality of life in patients with severe hip osteoarthritis. Pain Med. 2019:20(11):2220-7.

50. Gill TK, Tucker GR, Avery JC, Shanahan EM, Menz HB, Taylor AW, et al. The use of self-report questions to examine the prevalence of musculoskeletal problems: a test-retest study. BMC Musculoskelet Disord. 2016;17:100.

51. Broderick JE, Schneider S, Junghaenel DU, Schwartz JE, Stone AA. Validity and reliability of patient-reported outcomes measurement information system instruments in osteoarthritis. Arthritis Care Res (Hoboken). 2013; 65(10):1625-33.

\section{Publisher's Note}

Springer Nature remains neutral with regard to jurisdictional claims in published maps and institutional affiliations.

Ready to submit your research? Choose BMC and benefit from:

- fast, convenient online submission

- thorough peer review by experienced researchers in your field

- rapid publication on acceptance

- support for research data, including large and complex data types

- gold Open Access which fosters wider collaboration and increased citations

- maximum visibility for your research: over $100 \mathrm{M}$ website views per year

At BMC, research is always in progress.

Learn more biomedcentral.com/submissions 